\title{
Estratégias Competitivas no Setor Elétrico Brasileiro: uma Análise dos Interesses e Expectativas dos Atores da Chesf
}

\author{
Murilo Sergio Lucena Pinto \\ Rezilda Rodrigues Oliveira
}

\begin{abstract}
Resumo
O estudo focaliza aspectos políticos e estratégicos relativos à atividade de transmissão de energia da Chesf, considerando os possíveis impactos causados pelo processo de reestruturação e privatização do setor elétrico brasileiro. Foram realizadas entrevistas com stakeholders estratégicos, investigando interesses e expectativas da empresa e as mudanças ocorridas no contexto institucional recente, buscando-se demarcar fronteiras e atribuições a serem delineadas para a Chesf. Como resultado, foi-lhe sugerido adotar mecanismos mais competitivos e estruturas mais ajustadas à ambiência institucional de mudanças tecnológicas, de novas regras e de convivência com agentes em condições de parcerias estratégicas, visando à busca de novas oportunidades de negócios e de maior rentabilidade dos investimentos.
\end{abstract}

Palavras-chaves: estratégias; mudanças institucionais; Chesf; setor elétrico.

\begin{abstract}
The study focuses the political and strategical aspects related to the energy transmission activity of Chesf, considering the possible impacts caused by the Brazilian electric sector restructuring and privatization process. Interviews with strategical stakeholders were carried out, investigating their interests and expectations about this company and the changes occurred in the current institutional context, searching to demarcate borders and attributions to be delineated for Chesf. As result, it was suggested to adopt competitive mechanisms and more adjusted structures with the institutional environment of technological changes, new rules and close connections with agents in conditions of strategical partnerships, searching to reach new business opportunities and high returns for its investments.
\end{abstract}

Key words: strategies; institutional changes; Chesf; electric sector. 


\section{INTRODUÇÃo}

Este artigo apresenta como ponto de partida o contexto recente de grandes mudanças no setor elétrico brasileiro, sobretudo no que tange ao novo ambiente da indústria de energia elétrica, que passa por momento de profunda desinstitucionalização, correspondendo ao que Rowan (1982) identifica como resultante de alterações duradouras no mercado, mudanças radicais em tecnologias e na legislação.

Conforme demonstrado em estudo anterior (Pinto, 2001; Pinto e Oliveira, 2002), esse processo de desinstitucionalização (e re-institucionalização) representa um momento crítico para o setor elétrico do país, cujos legados históricos devem ser cuidadosamente examinados, com a elaboração de explicações concorrentes e o exame dos relacionamentos interorganizacionais que estão surgindo, em substituição aos arranjos antes prevalecentes, quando as condições eram estáveis e as operações se davam em contexto econômico, político e social bem diferente. Um detido olhar sobre essa questão permite ver que as mudanças verificadas no ambiente apontam para a introdução da competição em setor constrangido por grandes transformações, junto com o adensamento e a complexidade gerados pela implementação do programa de reestruturação e de privatização, cujos resultados sobre a atuação dos agentes econômicos merecem ser objeto de investigação.

Este estudo de caso na Companhia Hidro Elétrica do São Francisco (Chesf) tem como objetivo a delimitação dos possíveis impactos causados por essas mudanças na sua atividade de transmissão de energia. $\mathrm{O}$ fato de a experiência da Chesf ter sido acumulada em ambiente histórico-institucional diferente fez redobrar o interesse de se analisar a percepção de seus stakeholders sobre as mudanças ocorridas no setor elétrico, visando a orientar a sua atuação nesse novo desenho institucional. O estudo mostra que, no novo ambiente institucional do setor elétrico brasileiro, o papel da transmissão de energia da Chesf sofreu sensíveis mudanças, porquanto, se antes a atividade transmissão era apenas um segmento de uma empresa monopolística e verticalmente integrada, cuja receita dependia da venda de um produto (energia elétrica), hoje é um negócio independente, cuja receita depende da disponibilização dos ativos de transmissão existentes.

Vale ressaltar que, com mais de 50 anos de atuação, a Chesf é uma das maiores e mais importantes empresas do setor elétrico brasileiro, sendo responsável pela produção, transporte e comercialização de energia elétrica para oito Estados 
nordestinos ${ }^{(1)}$. Historicamente, suas origens remontam à atuação pioneira por ela desenvolvida, em decorrência da intervenção direta do poder público federal no campo da geração e transmissão de energia, em setor em que, antes de sua criação em 1945, era predominante a presença de empresas estrangeiras. Foi por meio da Chesf que o Estado brasileiro introduziu nova ordem técnica e industrial no Nordeste, em contraste com a linha tradicional de atuação clientelista e assistencialista por ele praticada nessa região e inaugurou novo estágio de desenvolvimento tecnológico no setor elétrico, a começar pela forma de exploração do potencial hidrelétrico nacional, sendo precursora do modelo de estatização posteriormente implantado no setor (Oliveira, 2001).

Partindo dessas premissas e reconhecendo a abrangência e complexidade do processo de reestruturação e privatização do setor elétrico brasileiro, a alternativa pela qual se optou aqui foi a de enfocar os aspectos políticos e estratégicos relacionados com a atividade de transmissão de energia, de modo a se chegar a uma abordagem que permitisse estabelecer uma demarcação de fronteiras e atribuições que possam ser vislumbradas para a Chesf. Na análise dos aspectos políticos, como recomenda Lamounier (1994), deve-se levar em conta o perfil dos atores envolvidos, a arena decisória em que atuam e o contexto institucional que circunscreve o fenômeno estudado. No plano estratégico, para se fazer essa análise recorreu-se à teoria dos stakeholders, com a qual se buscou identificar o conjunto de atores cujas decisões podem causar grande impacto nas organizações, sobretudo por serem eles detentores de expectativas e interesses capazes de determinar o seu destino e direcionamento.

Segundo Cummings e Doh (2000), o contexto político, social e tecnológico de uma empresa precisa ser por ela mais bem conhecido, se esta deseja incorporar ao seu escopo o amplo leque de instituições e atores - públicos e privados - que afetam sua operação. Nesse sentido, os stakeholders e seus múltiplos papéis representam importante elemento da análise da cadeia de valor de uma firma. Mais do que isso, eles podem provê-la de informações, competências e recursos para lidar com ambiente incerto e turbulento. Como é sabido, os stakeholders são indivíduos ou grupos de indivíduos que, direta ou indiretamente, podem afetar a organização ou ser afetados por ela na perseguição de seus objetivos (Stoner e Freeman, 1989).

Muitas vezes, os stakeholders reúnem grande potencial para influenciar tanto o ambiente como a estrutura, de acordo com a natureza do contexto institucional e os recursos postos à sua disposição. Lawrence (1999) sugere ser esse um assunto dos mais relevantes da teoria institucional, voltada para o entendimento de como os ambientes organizacionais são constituídos, reproduzidos e transformados por meio de ações movidas por indivíduos e grupos que atuam dentro e fora das 
organizações. Considerando que os stakeholders suprem a organização com importantes recursos ou contribuições, em resposta esperam que suas expectativas e interesses sejam satisfeitos por determinados incentivos. Por isso a teoria dos stakeholders requer não somente o entendimento do tipo de influência que eles exercem, mas também de como as organizações reagem às suas intervenções.

O estudo da Chesf em muito se beneficiou dessa abordagem, considerando-se que o conhecimento do ambiente político-institucional, que envolve as mudanças do setor elétrico, vistas sob a perspectiva dos stakeholders pesquisados, possibilitou obter-se uma contribuição acerca dos seus impactos, em particular aqueles referidos ao processo de formulação e de análise das alternativas estruturais das atividades de transmissão da empresa. As evidências empíricas que foram levantadas demonstram sua utilidade, na medida em que se fez a abordagem de um conjunto de atores com razoável poder nessa organização (Pinto, 2001). Para tanto, uma série de entrevistas foi realizada, contando-se com bom registro das observações e avaliações que fizeram, constituindo considerável acervo e instrumental analítico para melhor conhecer-se o espectro de mudanças em curso no ambiente competitivo do setor elétrico.

Na elaboração do trabalho obedeceu-se à seguinte estrutura: (1) breve referência ao histórico das mudanças institucionais verificadas na indústria de energia elétrica em suas diferentes dimensões, até mesmo relacionando-as com a discussão sobre o papel do Estado no setor elétrico brasileiro; (2) discussão sucinta do tema da competitividade, procurando-se levantar questões teóricas e técnicas relativas ao setor elétrico; (3) explicitação da metodologia utilizada para a identificação dos stakeholders internos e externos da Chesf; (4) análise da perspectiva dos stakeholders da atividade de transmissão da Chesf, considerando o contexto do processo de reestruturação e de privatização do setor elétrico; e (5) algumas considerações finais acerca da temática aqui apresentada.

\section{As Mudanças Institucionais na Indústria de Energia Elétrica}

O contexto das mudanças institucionais na indústria de energia elétrica não se restringe apenas ao Brasil. Em todo o mundo elas foram realizadas visando a aumentar a eficiência do setor elétrico, dando-se destaque à redução de custos, sobretudo pela introdução da competição, o que, em muitos casos, implica mudanças no papel do Estado. Na verdade, passou-se a realçar mais a intervenção estatal em termos regulatórios, tida como crucial para o funcionamento da indústria de energia elétrica. 
Nesse sentido, do ponto de vista das diferentes dimensões das mudanças que aqui são discutidas, a reestruturação e a privatização emergem como assuntos básicos. Não é recomendável tratar da questão da propriedade na indústria de energia elétrica, sem levar em consideração a sua estrutura e vice-versa (Hunt e Shuttleworth, 1996). De um lado, a reestruturação aparece como algo relacionado com os aspectos comerciais da venda de energia elétrica e, do outro, a privatização denota a transferência de serviços ou de atividades de produção, antes exercida pelo setor público, para empresas privadas ou para outras formas de organizações não-públicas (Mansiero e Saurin, 2000). Merece referência o fato de que, embora muitos países aleguem ser a privatização uma política relevante para seus vários setores industriais, nem sempre o setor elétrico é colocado no topo de suas prioridades ${ }^{(2)}$. Isto pode ser também observado na chamada era da Reforma do Estado, que apontou para o ressurgimento de idéias fundamentadas no argumento de que ele deveria retirar-se das atividades empresariais, redefinindo seus limites como produtor e assumindo o papel de regulador (Velasco, 1997).

A grande idéia que surgiu no novo mundo da competição da indústria de energia elétrica foi a possibilidade de separar, comercialmente, a energia, que passou a ser considerada um produto, do serviço de transporte realizado por meio das redes de transmissão de energia (Hunt e Shuttleworth, 1996).

Tal contexto de referência vem permeando o setor elétrico mundial, sendo que os ajustes feitos nas suas condições de funcionamento repercutem diferentemente, tanto em ritmo como em intensidade, de acordo com a realidade de cada país, respeitando-se aspectos tais como recursos naturais, tradição institucional e estilos de política. Mesmo assim, existem algumas características que são comuns aos processos de reforma que estão se desenvolvendo, como assinala Pinto (2001): (1) criação de um mercado de negociação competitiva de energia entre geradores, distribuidores e consumidores; (2) acesso às redes de transmissão e de distribuição em bases não-discriminatórias; (3) direito progressivo dos consumidores de escolher e negociar seu suprimento livremente com os geradores; e (4) constituição de agências reguladoras independentes.

No Brasil, o processo de reforma da indústria de energia elétrica reflete gradual processo de transição, com características que ainda não estão claramente definidas nem cristalizadas. Enquanto a orientação adotada em muito privilegiou a transferência de ativos do setor elétrico para o setor privado, a montagem e a execução das privatizações caminhou em paralelo com a construção do sistema regulatório (Gregório, 2000). É compreensível, então, que, apesar de haver relativo consenso quanto à necessidade de reformar o setor elétrico, ainda subsistam inúmeras dúvidas quanto à sua dimensão e, principalmente, ao ritmo de implementação da mudança institucional que lhe deve ser dado. Nesse sentido, os 
pressupostos básicos adotados pelo governo para a reestruturação do setor elétrico brasileiro foram os seguintes: ampliação da eficiência do setor; melhor alocação de recursos por meio da atração de grupos privados; garantia de recursos necessários à expansão; desverticalização do setor nos segmentos de geração, transmissão e distribuição; introdução da competição na geração e comercialização de energia; e, finalmente, mas não menos importante, redução da dívida pública.

Com efeito, o setor elétrico brasileiro está enfrentando um processo de desinstitucionalização. Em outras palavras, à saída de um padrão de institucionalização não tem correspondido a entrada de um substituto, convivendo-se com uma situação de entropia social (Jepperson, 1991). Esperase que esse estado de coisas venha a dar lugar à re-institucionalização, estabelecendo e legitimando um novo padrão, razão pela qual os agentes que nele atuam se mostram tão ansiosos por alcançarem outro patamar de institucionalização, justamente porque não se sabe quando e como isto irá acontecer. Para melhor esclarecer esse assunto, vale a pena fazer uma retrospectiva do papel do Estado no Brasil, considerando o contexto histórico-institucional do setor elétrico.

\section{O Papel do Estado no Brasil e o Setor Elétrico: Uma Retrospectiva}

A partir dos anos 70, começaram a surgir referências à crise do Estado, ressaltando-se a necessidade de se reduzir tanto seu papel como seu tamanho (Velasco, 1997). Segundo Bresser Pereira (1996), a causa da crise do Estado foi o seu excessivo crescimento, acentuando-se suas diferentes dimensões desde o Estado desenvolvimentista no Terceiro Mundo, ao Estado comunista no Segundo Mundo e ao welfare state no Primeiro Mundo. Nesse particular, é inegável a força da onda neoconservadora ou neoliberal que tomou conta dos Estados Unidos e dos demais países por ela atingidos. Na crítica neoliberal sempre predominou o pressuposto de que a solução para essa crise consistia na redução do tamanho do Estado, não devendo ele desempenhar nenhuma função econômica, exceto a de garantir os direitos de propriedade e a moeda nacional (Bresser Pereira, 1996).

No nosso país, em meio à desinstitucionalização e re-institucionalização vividas pelo setor elétrico, é reconhecida a falta de concepção mais explícita sobre a natureza e o papel do Estado, sobretudo quando se encerra um ciclo histórico governamental e a ascensão de outro. Em 2003, espera-se que seja iniciado um debate sobre os novos caminhos a serem seguidos. Segundo as diretrizes do novo governo, deverá ser adotado um modelo para o setor que enfatize mais o conceito de serviço público para as atividades de geração, transmissão e distribuição de energia elétrica, substituindo a visão puramente de mercado estabelecida pelo governo anterior (Instituto de Cidadania, 2002). 
Nesse sentido, Osborne e Gaebler (1998) entendem que o mercado livre, isento de qualquer influência governamental, não existe. Na discussão, evidencia-se um ambiente contemporâneo de rápidas mudanças, a exigir um tipo diferente de Estado, distanciado daquele da era industrial, com suas burocracias lentas e centralizadas, preocupado com normas e regulamentos, sujeito a cadeias de comando altamente hierarquizadas. No caso da privatização, que atingiu a maioria dos países, os programas que foram implementados procuravam alcançar três objetivos principais: reduzir o tamanho do Estado; aumentar a produtividade do sistema econômico; e reduzir o déficit público (Mansiero e Saurin, 2000). Sob esse aspecto, considera-se que os ganhos fiscais da privatização parecem ser essencialmente e em larga escala transitórios, notando-se a persistência da busca de eficiência, de modo a se obter um aumento sustentado de renda (Pinheiro, 1996). De todo modo, a idéia comumente veiculada de que a privatização, de per si, conduza à eficiência das empresas, tem sido alvo de muitas críticas e considerada desprovida de embasamento empírico e científico. Por esse ângulo, as privatizações devem ser acompanhadas de mecanismos de regulamentação e incentivo à competição por parte dos mercados, que são combinações possíveis para se organizar uma atividade econômica visando a determinado fim (Vinhaes, 1999).

O exame da história brasileira recente mostra que a indústria de energia elétrica passou de um modelo privado deficiente a um modelo estatal híbrido, em função das restrições político-ideológicas e de um quadro institucional e normativo inconsistente, nascido a partir da década de 60. Na formulação desse modelo, ocorreram dois movimentos distintos: um descentralizado, via os governos estaduais e suas concessionárias; outro centralizado, via o Governo Federal e suas empresas (Greiner, 1994). No final dos anos 70, as mudanças no padrão de financiamento do setor elétrico e as variadas crises enfrentadas pelo Estado culminaram nas reformas e ajustes praticados ao longo dos anos 80 e 90, dos quais resultaram os programas de privatização, a desregulamentação e a liberalização das importações.

As propostas surgidas ensejaram a mudança de um sistema construído com base no conceito de monopólio natural para um sistema de livre formação de preços, calcado na desverticalização das atividades de geração, transmissão, distribuição e comercialização de energia elétrica. Foi a partir daí que se passou a defender a quebra do monopólio das quatro geradoras federais do setor elétrico e a sua divisão em empresas menores, de modo a eliminar sua verticalização e aumentar o grau de concentração horizontal, além de encorajar a entrada de novos competidores no mercado e incentivar a rivalidade na indústria. Para tornar mais atrativo o interesse pelo novo modelo, em 1995, o processo de privatização foi iniciado pelas empresas distribuidoras, alcançando cerca de $70 \%$ delas em 
2001. O programa de privatização brasileiro incluiu as geradoras controladas pela Eletrobrás, ou seja, Chesf, Furnas, Eletronorte e Eletrosul, tendo esta última passado por processo de cisão que permitiu a privatização de seus ativos de geração no ano de 1998.

Por meio de um esquema incremental e extremamente volátil, conviveram juntos privatização, programas de reestruturação e o sistema remanescente estatal. Em 1996, o Projeto de Reestruturação do Setor Elétrico Brasileiro (Projeto ReSeb) teve seqüência com a contratação de uma equipe de consultores internacionais, liderados pela Coopers \& Lybrand, do Reino Unido. Por seu intermédio procurou-se: (1) introduzir e difundir mecanismos competitivos nos segmentos de produção e comercialização; (2) montar eficiente esquema de regulação para os serviços de transmissão e distribuição; e (3) estimular a criação de ambiente negocial mais transparente, de modo a gerar sinais claros para a atuação dos agentes e atrair investidores interessados na expansão do sistema elétrico (Pinto e Oliveira, 2002).

Uma questão central da reforma consistiu na descentralização das decisões de investimentos em novas fontes de geração e a possibilidade de opções de compra de energia por parte dos chamados Consumidores Livres (Maia, Pinto e Melo, 2000). Esse processo de transformação foi favorecido pela ênfase na adoção de dispositivos concorrenciais nos serviços públicos e na redução de restrições à participação privada nacional ou estrangeira, numa área antes reservada às concessionárias públicas. Desse modo, uma visão institucional do setor destaca a atuação de novas entidades como a Agência Nacional de Energia Elétrica (ANEEL), o Operador Nacional do Sistema (ONS) e o Mercado Atacadista de Energia (MAE).

Em paralelo com esses acontecimentos, as propostas de privatização das estatais federais foram sendo presumidas, entre elas sobressaindo o caso da Chesf, cuja cisão em três empresas foi cogitada entre os anos de 2001 e 2002, que se viu induzida a buscar inserir-se em ambiente competitivo, mesmo que sua propriedade tenha continuado estatal. Sobre o tema da competitividade discorrer-se-á a seguir.

\section{Competitividade nas Abordagens Econômica e Institucional}

Ao examinarem o fenômeno da competitividade, Machado-da-Silva e Fonseca (1999) defendem o uso de uma perspectiva integrada, construída com base nos pressupostos da abordagem econômica e da abordagem institucional, considerandoas facetas de uma mesma racionalidade concorrencial. Assim, a dimensão técnico- 
econômica supõe o uso da estratégia como instrumento de maximização da eficiência da organização em face de determinada condição de competição, caracterizando-se pela troca de bens e serviços. Já a dimensão político-institucional conduz ao estabelecimento e à difusão de regras de atuação e de representação de interesses, necessárias para o alcance da legitimidade organizacional.

Organizações submetidas às pressões do ambiente técnico-econômico e do ambiente político-institucional são avaliadas, respectivamente, tanto pela eficiência econômica quanto pela adequação às exigências sociais. Estas últimas constituem-se tanto em determinações de ordem formal e legal, quanto em pressões espontâneas, não-formalizadas.

De acordo com Carvalho, Vieira e Lopes (1999), à visão de um ambiente formado em sua totalidade por fluxos e intercâmbios técnicos há que se acrescentar um sistema de crenças e de normas institucionalizadas que, juntos, representam uma fonte independente de formas organizacionais racionais. Assim, o ambiente institucional representa um enriquecimento do que se compreende como ambiente técnico, ampliado ao domínio simbólico. Nos setores técnicos, as organizações colocam seus produtos e seus serviços no mercado, e são premiadas ao exercerem um contexto eficiente sobre o processo de trabalho, enquanto, nos setores institucionalizados, as organizações buscam apoio e legitimação de seu ambiente ao se conformarem com as normas e com os requisitos que este gera.

A existência de um ambiente não exclui, necessariamente, o outro. No processo de institucionalização, a utilização dos ambientes técnico e institucional é questão de grau (Scott e Meyer, 1991). A ênfase no contexto técnico não está errada, mas incompleta, pois relega atenção aos aspectos sociais e culturais das organizações e de seus ambientes. As abordagens econômicas e estratégicas têm seu foco principalmente nas relações de troca no ambiente técnico das organizações e na sua necessidade de adquirir e de controlar recursos escassos, em contexto de intensa competição por esses recursos, com o objetivo de assegurar o sucesso e a sobrevivência organizacional (Pfeffer e Salancik apud Oliver, 1997).

A concepção institucional do ambiente, em contraste, enfatiza o valor da sobrevivência e da conformidade, aderente às regras e às normas adotadas pelos agentes. As exigências do ambiente institucional especificam as estruturas e as atividades organizacionais que são, pública e coletivamente, vistas como apropriadas, legítimas ou socialmente aceitáveis.

De acordo com Oliver (1997), na dimensão do contexto ambiental, as demandas relativas à perspectiva institucional são de ordem política e legal, ao passo que no ambiente técnico, estas demandas estão relacionadas com os aspectos de mercado, cujas mudanças, quando de caráter estrutural, podem implicar o 
surgimento de processos de inovação tecnológica e da competitividade. Também cabe mencionar questões de ordem comportamental, com impactos importantes na formação de novos hábitos, crenças e ações coletivas ensaiadas por parte dos stakeholders envolvidos nesses processos. Neste trabalho, como referido anteriormente, a teoria dos stakeholders ofereceu importante contribuição para o caso da Chesf, ampliando o entendimento do papel dessa empresa em face do seu ambiente institucional, podendo com isso obter ganhos no gerenciamento de suas ações, na busca de garantir e manter não só competitividade mas legitimidade (Mitchell, Agle e Wood, 1997).

\section{Perspectiva Teórica dos Stakeholders}

A introdução do termo stakeholder na literatura de estudos organizacionais é relativamente recente, tendo sido apresentada por Edward R. Freeman em seu livro Strategic Management: A Stakeholder Approach, de 1984. Desde então, ocorreram várias contribuições para entender quem são os stakeholders para as organizações e quais são os stakeholders com quem os gerentes devem ter maior atenção (Mitchell, Agle e Wood, 1997).

A grande contribuição da teoria dos stakeholders para o estudo das organizações, de acordo com Martins e Fontes Filho (1999), é o fato de ela permitir tratamento mais abrangente dos múltiplos campos da racionalidade, em contraposição a enfoques reducionistas centrados no interesse do acionista (a teoria da firma) ou no interesse do cliente (gerência estratégica da qualidade). Essa visão, conforme Selznick (apud Martins e Fontes Filho, 1999), levaria a um obscurecimento das realidades acerca do poder, da subordinação e da realidade.

Segundo Hill e Jones (1998), como os stakeholders estão em constantes relações de troca com a empresa, eles podem supri-la com importantes recursos ou contribuições, cada um deles representando interesses a serem satisfeitos. Uma análise de quem são, quais são seus interesses e como eles atuam oferece grande ajuda na identificação de stakeholders críticos para a sobrevivência organizacional e na oferta de condições de atendimento de suas necessidades, bem como na reorientação de suas estratégias, podendo a organização firmar alianças com eles ou, quem sabe, até mesmo evitar desastrosos impactos no desempenho empresarial.

As definições do termo stakeholder variam de um extremo a outro, ao longo de um continuum, indo da mais ampla, que denomina stakeholder indivíduos ou grupos de indivíduos que, direta ou indiretamente, podem afetar a organização ou ser afetados por ela na perseguição de seus objetivos (Stoner e Freeman, 
1989), até a mais restrita, entendendo stakeholders como indivíduos ou grupos possuidores de expectativas sobre a organização, sem os quais esta não seria possível (Hill e Jones, 1998).

Um conceito mais amplo de stakeholders é cada vez mais necessário, na medida em que cresce a complexidade ambiental das organizações, tanto na perspectiva da dinâmica do ambiente externo quanto na do interno (Martins e Fontes Filho, 1999). Segundo Stoner e Freeman (1989), a sobrevivência de uma organização depende, freqüentemente, da sua habilidade em se adaptar às mudanças do mundo ao seu redor.

Os stakeholders podem ser divididos em externos e internos. Os stakeholders internos são os acionistas e empregados, incluindo os executivos, gerentes e membros do conselho da empresa. Os stakeholders externos são todos os outros indivíduos ou grupos que têm algum tipo de interesse na empresa. Tipicamente, este grupo compreende consumidores, fornecedores, governos, sindicatos, comunidades locais e o público em geral (Hill e Jones, 1998). A Figura 1 apresenta, de forma genérica, os stakeholders da Chesf, tanto internos como externos. Todos eles têm relação de troca com a empresa. Como referido anteriormente, cada grupo de stakeholders pode supri-la com importantes recursos ou contribuições, esperando algum tipo de retorno ou incentivo.

Figura 1: Stakeholders Internos e Externos da Chesf

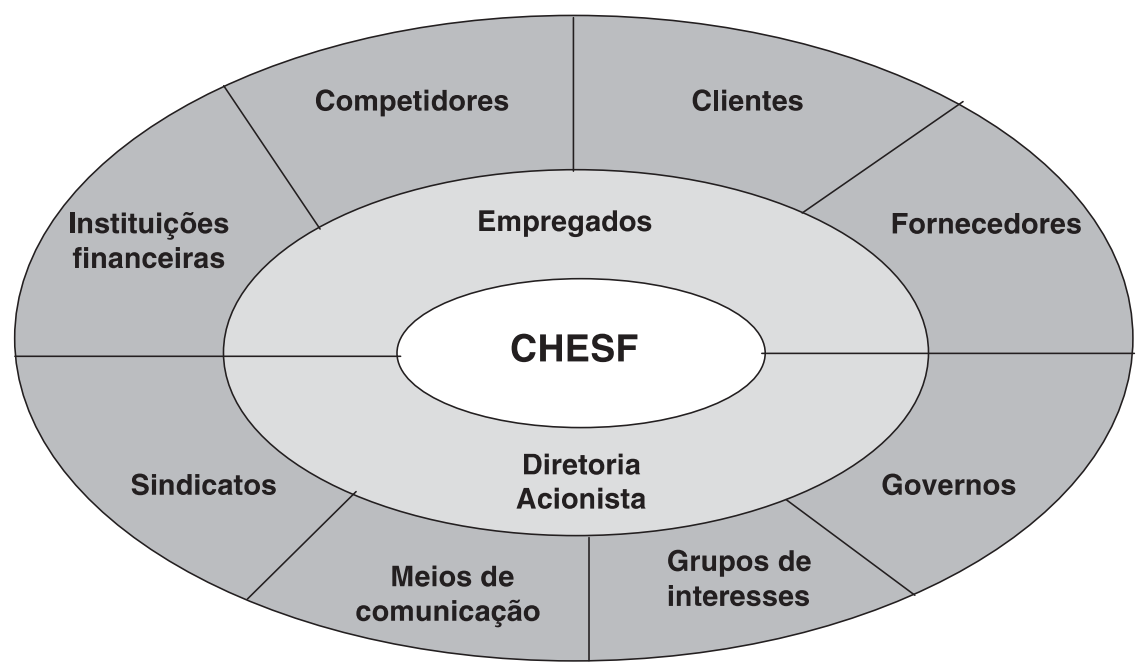

Stakeholders internos

Stakeholders externos

Fonte: adaptado de Stoner e Freeman (1989). 
De acordo com a literatura, por exemplo, acionistas provêem a organização com capital e, em troca, esperam retorno apropriado de seu investimento. Os empregados fornecem trabalho e habilidades e, em troca, esperam receber salário, satisfação, segurança e boas condições na realização de suas tarefas. Os consumidores proporcionam lucros para a organização e, em troca, desejam alta qualidade e confiabilidade nos produtos. Os governos fornecem as regras e regulamentos que orientam as práticas dos negócios e, em troca, querem que as organizações adiram a tais regras. Os sindicatos ajudam a prover as organizações com maior produtividade dos empregados e, em troca, desejam maiores benefícios para seus associados, proporcionais às suas contribuições para a empresa. O público consumidor fornece a infra-estrutura mercadológica e, em troca, busca alguma segurança para que a qualidade de vida seja melhorada como resultado da existência da empresa (Hill e Jones, 1998).

Segundo Frooman (1999), devem ser respondidas três perguntas gerais para se identificar os stakeholders: (1) Quem são eles? Esta questão visa a identificar os atributos dos stakeholders; (2) Que querem eles? Esta questão está centrada no interesse e nas preocupações dos stakeholders; (3) Como estão eles tentando alcançar seus objetivos? Esta questão está direcionada para a influência estratégica exercida pelos stakeholders nos desígnios organizacionais.

Conforme essa orientação, deve-se tentar identificar os stakeholders de acordo com os atributos que exibem em sua interação com a organização sobre a qual exercem influência e a capacidade de modificar seus destinos, de modo que atenda a seus interesses e preocupações. Essa idéia é reforçada por Rowley (1997), que sugere a investigação da reação das organizações a essa influência, constituindo uma via de mão dupla, ou seja, a teoria dos stakeholders supõe não somente entendimento do tipo de influência exercida pelo stakeholder, mas de como as organizações podem responder ou se adequar a essas influências.

Cada organização tem um quadro próprio de stakeholders. Uma rede complexa de relacionamentos liga os stakeholders entre si, bem como eles à organização. As organizações podem utilizar redes e coalizões de stakeholders para influenciar indiretamente outros stakeholders (Stoner e Freeman, 1989).

A Figura 2 apresenta um desdobramento dos stakeholders externos apresentados na Figura 1, com ênfase naqueles relacionados, especificamente, à atividade de transmissão de energia da Chesf. 


\section{Figura 2: Mapa dos Stakeholders da Atividade de Transmissão da Chesf}

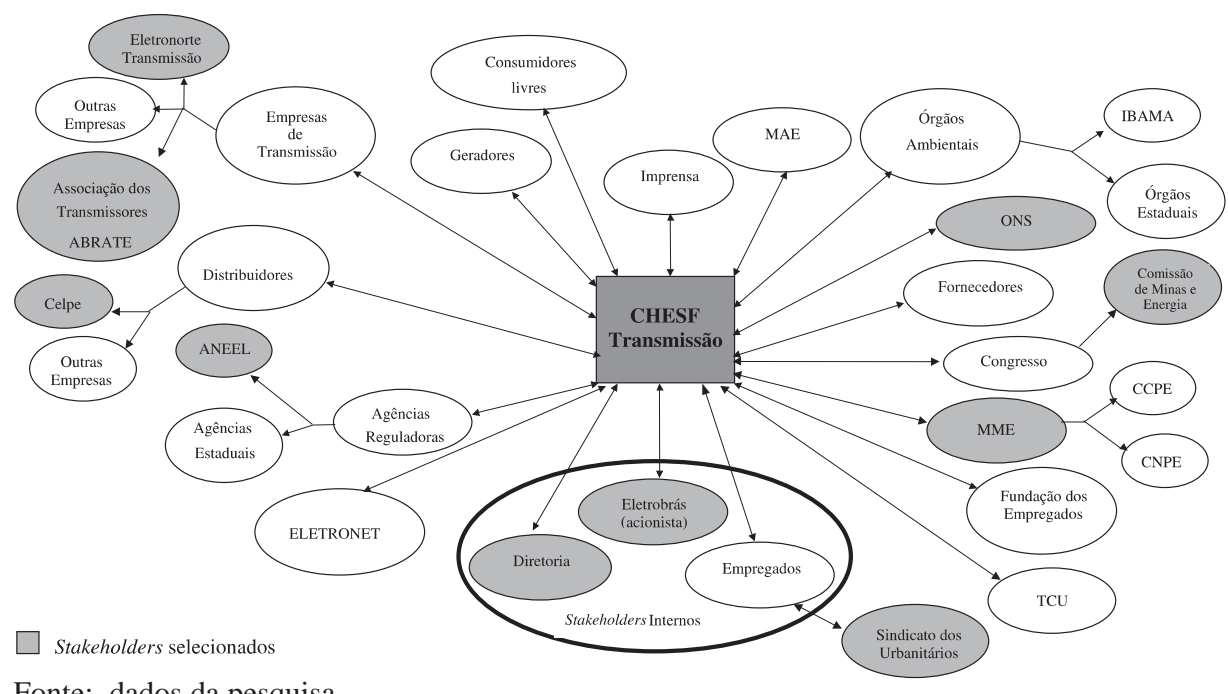

Fonte: dados da pesquisa.

Como o modelo institucional do setor elétrico brasileiro está atualmente em fase de detalhamento, os papéis dos diversos stakeholders externos ainda não foram devidamente compreendidos e/ou institucionalizados. Nesse processo, os stakeholders que surgem estão passando por fase de auto-afirmação de seus papéis, ao passo que outros, preexistentes, estão sofrendo verdadeira crise de identidade, enquanto não se define a sua situação, a exemplo da própria Chesf, cuja cisão e privatização esteve a ponto de acontecer.

Segundo Andrade, Dias e Quintella (1999), o processo de formação de estratégias competitivas ultrapassa os limites clássicos do planejamento técnicoeconômico e prolonga-se no espaço institucional da empresa, assumindo caráter permanente de mediação política e de construção de arranjos de negociação entre ela e seus diversos stakeholders. Essa negociação envolve acomodação, administração de divergências e elaboração de sucessivos acordos e convenções, em jogo mesclado por episódios simultâneos de conflito e cooperação.

\section{Visão dos Stakeholders Acerca dos Impactos na Chesf do Processo de Reestruturação e Privatização do Setor Elétrico}

Para a análise dos impactos das mudanças do setor elétrico brasileiro na atividade de transmissão de energia da Chesf, foram realizadas entrevistas semi- 
estruturadas com os seus principais stakeholders, tendo sido utilizadas questões abertas, de modo que fosse possível entender e captar a perspectiva dos participantes da pesquisa. Elaborou-se um roteiro prévio com cinco questões que serviram de guia durante as entrevistas. Segundo Richardson (1989), a entrevista semi-estruturada permite ao entrevistado desenvolver suas opiniões e informações da maneira que ele estimar conveniente. O entrevistador desempenha apenas as funções de orientação e estimulação.

No desenvolvimento da pesquisa, um ponto crucial foi a escolha dos stakeholders. Pelo mapa dos stakeholders apresentado na Figura 2, pode-se observar aqueles que foram destacados, cuja seleção se deu considerando a posição estratégica por eles ocupada em relação à atividade de transmissão de energia, bem como o fato de representarem organizações importantes do setor elétrico, sobretudo aquelas que tomam decisões que poderiam provocar maior impacto na Chesf. Levou-se em conta também suas preocupações e interesses, o que permitiu responder a segunda pergunta formulada por Frooman (1999). Assim, delineou-se o seu perfil institucional, envolvimento com a reforma do setor elétrico e contribuição que poderiam dar pelo conhecimento técnico e pelo interesse nos destinos da transmissão da Chesf. A terceira pergunta formulada por Frooman (1999), por razões de espaço e temática, constitui assunto de outro trabalho, em fase de elaboração.

Foram entrevistados o Diretor de Engenharia e Construção da Chesf (representando a diretoria da empresa), o Chefe de Gabinete da Presidência da Eletrobrás (representando o acionista) e o Presidente do Sindicato dos Trabalhadores nas Indústrias Urbanas no Estado de Pernambuco (representando os empregados), englobando os stakeholders internos. Com relação aos stakeholders externos, foram entrevistados: o Diretor do Departamento Nacional de Política Energética da Secretaria de Energia (representando o Ministério de Minas e Energia); o Diretor de Administração da Transmissão do Operador Nacional do Sistema (representando o sistema gestor da operação interligada); o Diretor de Coordenação Territorial da Companhia Energética de Pernambuco Celpe (representando as companhias distribuidoras integrantes da jurisdição da Chesf); o Diretor-Presidente da Eletronorte (representando as companhias geradoras e transmissoras federais); o Superintendente de Regulação da Transmissão da Aneel (representando a agência reguladora no que tange ao setor de transmissão); o Diretor e o Assistente Técnico da Associação Brasileira das Grandes Empresas de Transmissão de Energia (Abrate) e um Deputado Federal, participante da Comissão de Minas e Energia da Câmara dos Deputados. As entrevistas foram realizadas durante todo o ano de 2001.

Apresenta-se, no Quadro 1, uma breve identificação dos principais stakeholders, respondendo às duas primeiras perguntas estabelecidas por Frooman (1999), 

de transmissão de energia.

\section{Quadro 1: Identificação do Perfil e Interesses dos Principais Stakeholders da CHESF}

\begin{tabular}{|c|c|c|}
\hline Stakeholder & Quem são eles? & Que querem eles? \\
\hline Eletrobrás & $\begin{array}{l}\text { Empresa holding controladora da Chesf } \\
\text { e proprietária de } 99 \% \text { de suas ações. }\end{array}$ & $\begin{array}{l}\text { Obter retorno dos investimentos } \mathrm{e} \\
\text { viabilizar as políticas de interesse do } \\
\text { Governo Federal. }\end{array}$ \\
\hline Diretoria da Chesf & $\begin{array}{l}\text { Grupo responsável pela administração } \\
\text { da empresa. }\end{array}$ & $\begin{array}{l}\text { Defender o cumprimento das metas do } \\
\text { planejamento empresarial e dos interesses } \\
\text { dos acionistas e dos empregados. }\end{array}$ \\
\hline $\begin{array}{l}\text { Sindicato das Indústrias } \\
\text { Urbanas do Estado de } \\
\text { Pernambuco }\end{array}$ & $\begin{array}{l}\text { Entidade que representa os interesses } \\
\text { dos empregados das indústrias urbanas } \\
\text { do Estado de Pernambuco, onde se } \\
\text { encontra localizada a sede da Chesf. }\end{array}$ & $\begin{array}{l}\text { Defender o cumprimento dos acordos } \\
\text { coletivos e a participação dos empregados } \\
\text { nas decisões da empresa. }\end{array}$ \\
\hline $\begin{array}{c}\text { Ministério das Minas e } \\
\text { Energia }\end{array}$ & $\begin{array}{l}\text { Entidade responsável pela formulação } \\
\text { das políticas governamentais na área de } \\
\text { energia elétrica e pela elaboração do } \\
\text { planejamento da expansão do sistema } \\
\text { elétrico. }\end{array}$ & $\begin{array}{l}\text { Defender interesses do Governo Federal e } \\
\text { obter cooperação das empresas de } \\
\text { transmissão, na elaboração dos estudos de } \\
\text { planejamento para definição das } \\
\text { ampliações do sistema de transmissão. } \\
\text { Sua preocupação principal consiste na } \\
\text { receptividade e na adesão dos agentes aos } \\
\text { seus planos e políticas. }\end{array}$ \\
\hline $\begin{array}{c}\text { Comissão de Minas e } \\
\text { Energia da Câmara dos } \\
\text { Deputados } \\
\end{array}$ & $\begin{array}{l}\text { Comissão responsável pela análise das } \\
\text { políticas e desenvolvimento do setor } \\
\text { energético. }\end{array}$ & $\begin{array}{l}\text { Promover o debate permanente sobre as } \\
\text { questões energéticas do país. }\end{array}$ \\
\hline Aneel & $\begin{array}{l}\text { Entidade pública responsável pela } \\
\text { regulação do setor elétrico. Define a } \\
\text { receita das empresas de transmissão } \\
\text { associada aos ativos existentes e a } \\
\text { remuneração máxima associada aos } \\
\text { empreendimentos futuros. Suas ações } \\
\text { podem ter grande impacto no equilíbrio } \\
\text { econômico-financeiro das empresas. }\end{array}$ & $\begin{array}{l}\text { Responder principalmente pela garantia da } \\
\text { disponibilidade universal do serviço de } \\
\text { energia elétrica, incentivando a } \\
\text { competição nos segmentos de geração e de } \\
\text { comercialização, garantindo o livre acesso } \\
\text { ao sistema de transmissão, bem como a } \\
\text { conquista de alto nível de eficiência e de } \\
\text { confiabilidade a preços razoáveis. }\end{array}$ \\
\hline Eletronorte & $\begin{array}{l}\text { Empresa controlada pela Eletrobrás, } \\
\text { responsável pela geração, transmissão e } \\
\text { comercialização de energia para os } \\
\text { estados da Região Norte. }\end{array}$ & $\begin{array}{l}\text { Defender interesses competitivos em } \\
\text { relação aos novos empreendimentos de } \\
\text { transmissão, em particular, nas grandes } \\
\text { interligações entre as regiões Norte e } \\
\text { Nordeste. }\end{array}$ \\
\hline ONS & $\begin{array}{l}\text { Entidade privada responsável pela } \\
\text { coordenação e pelo controle da } \\
\text { operação da geração e da transmissão } \\
\text { de energia. Suas ações têm influência } \\
\text { no dia-a-dia das empresas de } \\
\text { transmissão, podendo comprometer o } \\
\text { seu desempenho econômico-financeiro, } \\
\text { na medida em que suas decisões } \\
\text { venham a afetar a parcela variável da } \\
\text { receita permitida, associadas às } \\
\text { indisponibilidades de elementos do } \\
\text { sistema. }\end{array}$ & $\begin{array}{l}\text { Defender interesses e preocupações } \\
\text { relacionados com a maximização, } \\
\text { disponibilidade das fontes geradoras e } \\
\text { minimizar as restrições de transmissão. }\end{array}$ \\
\hline Celpe & $\begin{array}{l}\text { Empresa privada, com concessão para } \\
\text { distribuir energia elétrica no Estado de } \\
\text { Pernambuco. Tem suas instalações } \\
\text { interligadas à rede de transmissão da } \\
\text { Chesf. }\end{array}$ & $\begin{array}{l}\text { Defender os interesses de seus acionistas, } \\
\text { realizando suas operações com } \\
\text { confiabilidade, qualidade do sistema de } \\
\text { transmissão e encargos de conexão e uso. }\end{array}$ \\
\hline Abrate & $\begin{array}{l}\text { Associação que representa os interesses } \\
\text { do segmento das grandes empresas de } \\
\text { transmissão de energia em todo o } \\
\text { território nacional. }\end{array}$ & $\begin{array}{l}\text { Promover a atuação coordenada das } \\
\text { empresas de transmissão, visando à defesa } \\
\text { dos interesses de seus associados. }\end{array}$ \\
\hline
\end{tabular}

Fonte: dados da pesquisa. 
A análise das entrevistas realizadas apoiou-se na categorização de temáticas, préselecionadas, tendo sido extraídos delas alguns trechos representativos das falas dos stakeholders. De acordo com Bardin (1977), o tema é uma unidade de significação complexa de comprimento variável, e a sua validade não é de ordem lingüística, mas antes de ordem psicológica. Fazer uma análise temática consiste em descobrir os núcleos de sentido que compõem a comunicação e cuja presença pode significar alguma coisa para o problema em análise. O tema é geralmente utilizado para estudar motivações de opiniões, de atitudes, de valores, de crenças e de tendências. Assim, foram definidos temas principais e secundários, obedecendo à metodologia proposta por Richardson (1989). Segundo o autor, temas principais definem o conteúdo da parte analisada de um texto, e os secundários especificam diversos aspectos contidos nos primeiros. A análise temática teve caráter transversal, isto é, as entrevistas foram recortadas em redor de cada tema, englobando tudo o que é afirmado acerca de cada um deles no decorrer das entrevistas, independentemente do momento em que a afirmação tenha tido lugar, com transcrição para uma ficha.

Com base na opção metodológica adotada, as entrevistas realizadas com os stakeholders foram analisadas considerando os temas principais e secundários apresentados no Quadro 2.

\section{Quadro 2: Temas Principais e Secundários da Pesquisa na Perspectiva dos Stakeholders}

\begin{tabular}{|c|c|}
\hline Temas Principais & Temas Secundários \\
\hline \multirow{2}{*}{$\begin{array}{c}\text { Processo de reestruturação e privatização do setor } \\
\text { elétrico }\end{array}$} & Desverticalização da Chesf \\
\cline { 2 - 2 } & Privatização da transmissão \\
\cline { 2 - 2 } & Modelo do setor elétrico \\
\cline { 2 - 2 } Atuação da transmissão da Chesf & Outros modelos para a Chesf \\
\hline \multirow{2}{*}{ Competitividade da transmissão } & Missão da transmissão \\
\cline { 2 - 2 } & Papel institucional e responsabilidades \\
\cline { 2 - 2 } & Ações para aumento da competitividade \\
\cline { 2 - 2 } & Vantagens competitivas da Chesf \\
\cline { 2 - 2 } & Capacitação técnica e gerencial \\
\hline \multirow{2}{*}{ Problemática atual } & Crise energética \\
\cline { 2 - 3 } & Processo político eleitoral \\
\hline
\end{tabular}

Fonte: dados da pesquisa.

Para cada um dos temas foi realizada uma análise detalhada das posições dos stakeholders, cujo resumo, feito por tema secundário, consta do Quadro 3. 


\title{
Quadro 3: Resumo das Perspectivas dos Stakeholders da Chesf por Tema Secundário
}

\begin{abstract}
Tema - Desverticalização. A maioria dos stakeholders considerou ser necessária a desverticalização da Chesf, com a separação das atividades de geração e transmissão, por meio da constituição de empresas independentes. Essa condição foi apresentada como essencial para o adequado funcionamento do modelo do setor elétrico, que tem como um dos pressupostos a competição na geração. Segundo eles, essa competição poderia ser afetada pelo fato de uma empresa de geração também ser proprietária de uma rede de transmissão e utilizar esta condição para tirar vantagens competitivas, por meio de subsídios cruzados ou impondo condições que afetem outros agentes de geração. Por outro lado, alguns stakeholders entenderam ser necessário realizar apenas a separação contábil das atividades de geração ou de transmissão, julgando possível exercer um controle sobre essas atividades e garantir, dessa forma, a neutralidade da transmissão.
\end{abstract}

Tema - Privatização da transmissão. Embora existissem visões opostas com relação ao tema da privatização, os stakeholders concordaram unanimemente que estava esgotado o modelo atual de gestão das empresas estatais. Alguns deles entenderam que a privatização da transmissão da Chesf seria a melhor alternativa para a solução do problema. Já outros entenderam que a transmissão deveria permanecer estatal, porém com mudanças na forma de atuação da empresa. De acordo com alguns stakeholders, o tipo de propriedade da transmissão não é relevante para o adequado funcionamento do setor elétrico, em função da forma como foram transferidas para o ONS as responsabilidades pela gestão da transmissão, que antes eram das empresas detentoras do controle da operação em suas áreas de atuação, como no caso da Chesf. Um importante aspecto levantado foi a discussão da privatização da geração da empresa, a qual deveria preceder a da privatização da transmissão. A privatização da transmissão já estaria ocorrendo na expansão, visto que cada novo empreendimento na transmissão estava sendo encaminhado pelo Governo ao Conselho Nacional de Desestatização e submetido a processo de leilão. A orientação do Governo era de que os investimentos fossem realizados prioritariamente pela iniciativa privada.

Tema-Modelo do setor elétrico. Os stakeholders posicionaram-se sobre a necessidade de realizar ajustes no modelo do setor elétrico que estava sendo implantado no Brasil, devendo ser avaliadas as suas premissas básicas e os aspectos que levaram à crise energética em 2001. Segundo um dos stakeholders, um aspecto que dificultou a implantação do novo modelo foi a discussão simultânea da reestruturação e privatização do setor. Na visão dos stakeholders, a questão mais importante a ser discutida deveria ser o papel das empresas estatais e, em particular, o destino das empresas de geração e da energia por elas gerada. Com relação à transmissão, foi destacada a necessidade de realizar avanços na sua regulação. Alguns stakeholders entenderam que um modelo para o sistema de transmissão com múltiplos proprietários funcionava adequadamente. Já um deles entendeu que esse modelo deveria receber ajustes, para evitar casos nos quais venham a existir vários agentes atuando em uma mesma instalação. 


\title{
(continuação) \\ Quadro 3: Resumo das Perspectivas dos Stakeholders da Chesf por Tema Secundário
}

\begin{abstract}
Tema - Outros modelos para a Chesf. Os stakeholders também se posicionaram em relação a outros modelos organizacionais para a Chesf que estavam em discussão no setor elétrico, à época. Um deles viria a ser o modelo de criação de uma empresa holding e privatização por meio da pulverização de ações. Alguns stakeholders acharam esse modelo viável, enquanto outros entenderam que a Chesf deveria ser separada em empresas de geração e de transmissão. Por outro lado, a maioria dos stakeholders entendeu que a pulverização de ações seria a melhor forma de privatizar a geração da Chesf. Um aspecto que também chamou a atenção dos stakeholders referiu-se à definição do modelo organizacional para a Chesf, no qual dever-se-ia levar em consideração a importância da empresa para a Região Nordeste e a sua vinculação com o Rio São Francisco. No caso de a empresa ser mantida estatal, julgaram que a sociedade deveria exercer maior controle sobre ela. Um dos stakeholders apresentou uma proposta de modelo para a Chesf, consistindo na criação de duas empresas integradas de geração e de transmissão, no qual uma delas teria responsabilidade sobre as obras de reestruturação hídrica do Nordeste, começando com a recuperação do Rio São Francisco.
\end{abstract}

Tema - Missão da transmissão. Segundo um dos stakeholders, ficava difícil pensar em uma missão para o segmento de transmissão com a Chesf ainda íntegra. Os stakeholders entenderam que a missão básica da atividade de transmissão de energia da Chesf seria a de oferecer máxima disponibilização de seus ativos. Como no modelo vigente para a transmissão não existia mais a concessão por área geográfica, a Chesf deveria buscar ampliar suas fronteiras. Alguns stakeholders discutiram uma missão mais ampliada, na qual além da disponibilização dos ativos existentes e da prestação de serviços, a empresa deveria buscar novos ativos, por meio da participação nos leilões de concessão de transmissão. Um dos stakeholders comentou ser fundamental que a empresa tivesse uma visão de expansão, apesar da existência de dificuldades, por ser estatal, para ela participar dos leilões de concessão de novos empreendimentos de transmissão.

Tema - Papel institucional e responsabilidade. Muitas eram as visões opostas dos stakeholders sobre o papel institucional e a responsabilidade da Chesf transmissão na Região Nordeste. Alguns entendiam que o seu papel de empresa regional, pensando no atendimento de energia ao Nordeste e em sua atuação como integradora das empresas da região, iria diminuir com o tempo, na medida em que fossem aparecendo novos agentes na região, devendo a empresa voltar-se para a administração de seus ativos. Por outro lado, outros stakeholders entenderam que a empresa deveria continuar atuando como agente de integração dos Estados da região, devendo até mesmo ampliar o seu papel e ser instrumento de desenvolvimento regional. 


\title{
(continuação) \\ Quadro 3: Resumo das Perspectivas dos Stakeholders da Chesf por Tema Secundário
}

\begin{abstract}
Tema - Ações para aumento da competitividade. Alguns stakeholders argumentaram que um aspecto limitante da competitividade da Chesf consistia no fato de ela ser uma empresa estatal. Um dos stakeholders entendeu que esse aspecto poderia ser atenuado com a utilização do contrato de gestão. Já outro stakeholder entendeu que as atividades relacionadas aos ativos existentes não seriam afetadas pela razão de a empresa ser estatal ou privada. A agilidade necessária nas ações relacionadas com a expansão é que poderia ser prejudicada em função de a Chesf ser estatal. As ações para aumento de competitividade poderiam ser diferenciadas com relação aos ativos existentes e aos novos ativos. Quanto aos ativos existentes, as ações estariam mais vinculadas com a melhoria dos seus processos internos de operação e de manutenção e toda a logística associada, para redução de custos e otimização principalmente das atividades de manutenção. Com relação às estratégias de expansão, as visões eram de que a Chesf teria que se aparelhar e desenvolver habilidades que lhe permitissem vir a ser competitiva nos leilões. Suas ações deveriam concentrar-se na busca da forma mais econômica possível para o projeto, construção, especificação e estudos dos equipamentos, visando a otimizar ao máximo as propostas para os leilões de que ela participasse.
\end{abstract}

Tema - Vantagens competitivas. Na visão dos stakeholders, a Chesf transmissão reunia as seguintes vantagens competitivas: grande volume de ativos; tamanho de seu sistema; infra-estrutura instalada; experiência de atuação em redes energizadas; experiência em linhas longas; diversificação de equipamentos; estoque de conhecimento acerca do Nordeste; e posse de um sistema que abrange toda a região. Um dos stakeholders entendeu que as atuais vantagens competitivas da empresa, em particular, o conhecimento da região, não eram tão significativas quando comparadas com as novas exigências vigentes no ambiente do setor elétrico, em função da entrada de novos agentes de transmissão com novas tecnologias e bastante preparo, devendo a empresa realizar mudanças na sua forma de gestão.

Tema - Capacitação técnica e gerencial. De acordo com os stakeholders, com relação às instalações de transmissão que estavam em operação, deveria ser dada ênfase à capacitação gerencial e à redução de custos, além da capacitação técnica voltada para a operação e para a manutenção, visando a reduzir ao máximo a indisponibilidade dos equipamentos. Para as atividades de expansão da transmissão, relacionadas à disputa de leilões de novas instalações, a ênfase da capacitação deveria ser voltada para a área de negócios e também para as mudanças nos aspectos técnicos do planejamento, do projeto, da construção, da especificação das novas instalações, objetivando torná-las o mais econômicas possível, visando a ganhar os leilões. Com relação às atividades relacionadas à prestação de serviços, a empresa deveria capacitar-se na área negocial, além de também ter de investir na capacitação do pessoal atuante nas áreas de contratos e de regulação. 


\section{(conclusão) \\ Quadro 3: Resumo das Perspectivas dos Stakeholders da Chesf por Tema Secundário}

Tema - Crise energética. Segundo os stakeholders, juntamente com a crise energética, eclodiram questionamentos sobre o modelo do setor elétrico brasileiro, questões estas que estavam “embaixo do tapete”, enquanto, em alguns países, já se discutia a reforma da reforma do setor elétrico. Um dos stakeholders tinha uma visão negativa em relação ao futuro do setor. Na sua opinião, ainda deveriam ocorrer outras crises, devido à complexidade do setor elétrico brasileiro e às incertezas do ambiente político. Outro stakeholder entendeu que a crise traria impactos positivos para a Região Nordeste, pela possibilidade de aumento da importação de energia da Região Norte e de maior utilização do Rio São Francisco para outros fins que não fosse apenas para a produção de energia.

Tema - Processo político-eleitoral. Na visão dos stakeholders, o processo políticoeleitoral do ano de 2002 poderia trazer mudanças significativas para o setor elétrico. Um dos stakeholders argumentou que não esperava grandes mudanças no então governo, sugerindo que fossem efetuadas apenas algumas adaptações no modelo vigente, mantendo-se as premissas básicas de busca da competição nas atividades de geração e de comercialização, bem como a priorização de investimentos privados. Em relação ao próximo governo, a percepção era de que tudo dependia do perfil das alianças forjadas para sua sustentação, para tanto vislumbrando-se tanto um cenário de manutenção das bases do então modelo, com a realização de alguns ajustes, como outro no qual ocorreria uma ruptura de suas premissas básicas. Um stakeholder externou sua preocupação quanto ao controle das eventuais mudanças radicais e aos riscos de instabilidade no setor elétrico. Um aspecto que, possivelmente, faria parte da agenda do próximo governo, seria o da discussão do papel do Estado.

\section{Considerações Finais}

Não há dúvida de que as transformações ocorridas nos últimos anos na indústria brasileira de energia elétrica tiveram grandes impactos nas empresas do setor. Neste artigo, espera-se que a análise do ambiente político-institucional e técnico tenha fornecido elementos para melhor se compreender as dimensões dessas mudanças, cuja discussão teve caráter teórico e empírico.

No estudo da Chesf, a teoria dos stakeholders foi decisiva para o alcance dos objetivos do trabalho, pois a forma como foi levantado seu posicionamento tornou possível identificar importantes aspectos que poderão subsidiar a empresa, para que possa desenvolver certas ações ou mesmo proceder ao realinhamento de 
suas atividades de transmissão, tendo em vista o atual ambiente competitivo do setor elétrico. Em relação a esse aspecto, tem-se em mente que está emergindo nova cultura, refletida na capacidade que tiveram os seus stakeholders de expressá-la, quando convidados a mostrar seu poder de influência e formação de opinião acerca do assunto. Nesse sentido, o perfil dos stakeholders entrevistados mostra que eles representam desde os interesses do órgão regulador até aqueles relativos ao destino da empresa como agente desenvolvimentista.

Cabe aqui mencionar as limitações que um estudo de caso tem, tanto em termos de generalização como de abordagem, identificada com a visão do pesquisador e suas idiossincrasias, que respondem pela escolha dos temas principais levantados, bem como por seus desdobramentos para temas secundários. Os próprios stakeholders selecionados foram induzidos a tratar do assunto conforme a orientação dada à pesquisa, cujo roteiro foi previamente acertado com eles. Outra questão importante diz respeito ao momento em que a pesquisa foi realizada. Hoje, inegavelmente, a questão da privatização parece estar afastada. Continua, entretanto, a agenda da reestruturação do setor elétrico, especialmente com relação aos efeitos das mudanças tecnológicas, à criação de instituições, de regras e de normas, além da introdução e convivência com as forças de mercado.

Da perspectiva dos stakeholders, pôde-se apreender que o processo de reestruturação e de privatização do setor elétrico alerta para as profundas marcas deixadas sobre a identidade, valores, visão de futuro e estratégia da Chesf, com sérias repercussões no aprendizado que ela hoje desenvolve e ainda deverá desenvolver nos próximos anos. Mesmo que permaneça estatal, acredita-se que não há como a empresa se divorciar da adoção de mecanismos competitivos e de estruturas mais ajustadas com a ambiência institucional de mudanças tecnológicas, de novas regras, de convivência com agentes em regime de parcerias estratégicas, visando à exploração de novas oportunidades de negócios e de maior rentabilidade dos investimentos, indo além de suas atividades finalísticas originais.

Com relação ao tema missão institucional da Chesf, por exemplo, a maioria dos stakeholders sinalizou para o fato de que a atividade de transmissão de energia deve privilegiar a máxima disponibilidade das instalações existentes. Contudo, para outros stakeholders, a empresa deve também participar dos leilões de concessão de transmissão e explorar a prestação de serviços, expandindo e inovando as suas atividades. Eles alertaram para a sua falta de agilidade para entrar nesse mercado, porquanto, por ser estatal, isto constitui fator limitante para sua competitividade. Nesse ambiente de negócios, um dos stakeholders observou que uma alternativa poderia ser a utilização de contratos de gestão, que lhe facultaria atuar em condições de igualdade com os agentes privados. 
Foi relevante o destaque dado por um stakeholder, ao distinguir o uso pela Chesf de estratégias de ação para os ativos atualmente existentes em relação às estratégias para obtenção de futuros ativos. Segundo ele, no que se refere aos ativos existentes, as ações estariam mais vinculadas à melhoria dos seus processos internos de operação e de manutenção e toda a logística associada, visando a reduzir custos e a otimizar cada instalação do sistema. Caso a Chesf venha a participar dos leilões de novos ativos, recomendam os stakeholders que ela esteja plenamente aparelhada e apta a ser competitiva, o que não ocorre no momento.

Outro ponto abordado foram as vantagens competitivas apresentadas pela Chesf, que podem não ser tão significativas, quando comparadas com as novas exigências do ambiente, em função da entrada de novos agentes de transmissão detentores de tecnologias mais atuais, até mesmo no que concerne à gestão. Dessa forma, deve ser dada ênfase à sua capacitação técnica e gerencial, visando à área negocial, de contratos e de regulação.

Muito teria ainda a ser dito quanto ao conjunto de dados levantado e que merece maior aprofundamento. Todavia isso fugiria ao escopo e ao espaço de um artigo. Para finalizar, cabe mencionar que a análise aqui realizada demonstra que a Chesf está assistindo à construção de nova etapa de sua história, fortemente vinculada a escolhas com que nem todos os seus stakeholders concordam e reconhecem como suas, mas que influenciam a regra do jogo e seu comportamento político, podendo contribuir para que o projeto institucional da empresa seja representativo de propósitos que eles próprios tenham que vir a legitimar ou a alterar, em consonância com o contexto social, político, econômico e cultural. Mitchell, Agle e Wood, 1997) atribuem aos stakeholders grande capacidade para exercer poder e legitimidade no curso de sua ação política e das coalizões que formam em torno de questões essenciais para a corporação e a construção social de agendas que lhes interessam, destacando a saliência e o dinamismo que podem assumir na defesa de uma causa.

\section{Notas}

${ }^{1}$ A Chesf (2003) possui atualmente capacidade de geração de energia de 10.705 megawatts, sendo 10.271 megawatts de origem hidraúlica, 432 megawatts de origem termelétrica e 1,2 quilowatts de origem eólica. É a empresa com o maior parque gerador do Brasil.

${ }^{2} \mathrm{O}$ caso norueguês pode ser considerado um exemplo de reestruturação sem privatização do setor elétrico, em que apenas 15\% das empresas são corporações privadas. A Noruega foi uma das pioneiras na introdução das bases para um mercado competitivo de energia elétrica por meio do Energy Act de 1991 (Gilbert e Kahn, 1998).

Artigo recebido em 24.07.2003. Aprovado em 01.12.2003. 
REFERÊNCIAS BIBLIOGRÁFICAS

ANDRADE, J. C. S.;

DIAS, C. C.;

QUINTELLA, R. H.

A dimensão político-institucional das estratégias sócio-ambientais: o jogo Aracruz Celulose S.A. - Índios tupiniquins e guaranis. In: ENCONTRO ANUAL DA ANPAD, 23., 1999, Foz do Iguaçu. Anais... Foz do Iguaçu: ANPAD, 1999. 1 CDROM.

BARDIN, L.

Análise de conteúdo. Lisboa: Edições 70, 1977.

BRESSER PEREIRA, L. C.

Crise econômica e reforma do Estado no Brasil. São Paulo: Editora 34, 1996.

CARVALHO, C. A. P.;

VIEIRA, M. M. F.;

LOPES, F. D.

Contribuições da perspectiva institucional na análise das organizações. In: ENCONTRO ANUAL DA ANPAD, 23., 1999, Foz do Iguaçu. Anais... Foz do Iguaçu: ANPAD, 1999. 1 CD-ROM.

\section{CHESF.}

Disponível em <http:// www.chesf.gov.br>. Acesso em: 12 fev. 2003.

\section{COOPERS \& LYBRAND.}

Etapa VII - projeto de reestruturação do setor elétrico brasileiro. Relatório consolidado. Relatório principal. Brasília, SEN/Eletrobrás, 1997. v. II.
CUMMINGS, J. L.;

DOH, J. P.

Identifying who matters - mapping key players in multiple environments. California Management Review, v. 42, n. 2, p 83-102, 2000.

FROOMAN, J.

Stakeholder influences strategies. Academy of Management Review, v. 24, n. 2, p. 191-205, Apr. 1999.

GILBERT, R. J.;

KAHN, E. P.

International comparisons of electricity regulation. Cambridge, MA: Cambridge University Press, 1998.

GREGÓRIO, T. A.

$O$ custo de uma concessão e a privatização no setor elétrico brasileiro. Florianópolis, 2000. Dissertação (Mestrado em Engenharia de Produção) - Universidade Federal de Santa Catarina.

\section{GREINER, P.}

Bases para um modelo autoregulador para o setor elétrico brasileiro. São Paulo, 1994. Tese (Doutorado em Administração Contábil e Financeira) - Escola de Administração de Empresas de São Paulo, Fundação Getúlio Vargas.

HILL, C. W. L.;

JONES, G. R.

Strategic management theory: an integrated approach. 4. ed. Boston: Houghton Mifflin Company, 1998. 
HUNT, S.;

SHUTTLEWORTH, G.

Competition and choice in electricity. New York: John Wiley \& Sons, 1996.

\section{INSTITUTO DE CIDADANIA.}

Diretrizes e linhas de ação para o setor elétrico. Rio de Janeiro, Projeto Energia Elétrica, 2002.

JEPPERSON, R. L.

Institutions, institutional effects, and institutionalism. In: POWELL, W. E.; DIMAGGIO, P. J. (Eds.). The new institutionalism in organizational analysis. Chicago: The University of Chicago Press, 1991.

\section{LAMOUNIER, B.}

Determinantes políticos da política agrícola: um estudo de atores, demandas e mecanismos de decisão. Rio de Janeiro: IPEA, 1994.

\section{LAWRENCE, T. B.}

Institutional strategy. Journal of Management, v. 25, n. 2, p. 161-188, Mar./Apr. 1999.

\section{MACHADO-DA-SILVA, C. L.;}

FONSECA, V. S. DA.

Competitividade organizacional: uma tentativa de reconstrução analítica. In: VIEIRA, M. M. F.; OLIVEIRA, L. M. B. (Orgs.). Administração contemporânea: perspectivas estratégicas. São Paulo: Atlas, 1999.

MAIA, M. J. A.;

PINTO, M. S. L.;

MELO, P. A.

Marcos regulatórios para o sistema elétrico brasileiro e seus rebatimentos nas empresas de transmissão. In:
SIMPÓSIO DE ESPECIALISTAS

EM PLANEJAMENTO DA OPERAÇÃO E EXPANSÃO ELÉTRICA, 7., 2000, Curitiba. Anais... Curitiba: SEPOPE, 2000. 1 CD-ROM.

MANSIERO, G.;

SAURIN, V.

A disseminação da política de privatização pelo mundo. Revista de Estudos Organizacionais, v. 1, n. 1, p. 107-124, jan./jun. 2000.

MARTINS, H. F.;

FONTES FILHO, J. R.

¿En quién se pone el foco? Identificando stakeholders para la formulación de la misión organizacional. Revista del CLAD Reforma y Democracia, n.15, p. 111140, oct. 1999.

MITCHELL, R. K.;

AGLE, B. R.;

WOOD, D. J.

Toward a theory of stakeholder identification and salience: defining the principle of who and what really counts. Academy of Management Review, v. 22, n. 4, p. 853-886, oct. 1997.

OLIVEIRA, R. R.

A CHESF e o papel do Estado na geração de energia elétrica. Revista Econômica do Nordeste, v. 32, n. 1, p. 10-35, jan./mar. 2001.

OLIVER, C.

The influence of institutional and task environment relationship on organizational performance. Journal of Management Studies, v. 34, n. 1, p. 99-124, 1997. 
OSBORNE, D.;

GAEBLER, T.

Reinventando o governo: como o espírito empreendedor está transformando o setor público. Brasília: Editora MH Comunicação, 1998.

PINHEIRO, A. C.

No que deu, afinal, a privatização? Rio de Janeiro: BNDES, 1996. Texto para discussão. n. 40.

PINTO, M. S. L.

A reestruturação e a privatização do setor elétrico brasileiro e os impactos sobre a transmissão de energia da CHESF na visão de seus stakeholders. Recife, 2001. Dissertação (Mestrado em Administração) Universidade Federal de Pernambuco.

PINTO, M. S. L. et al.

O novo cenário institucional do setor elétrico e seus reflexos nas empresas de transmissão. In: SIMPÓSIO DE ESPECIALISTAS EM PLANEJAMENTO DA OPERAÇÃO E EXPANSÃO ELÉTRICA, 7., 2000, Curitiba. Anais... Curitiba: SEPOPE, 2000. 1 CD-ROM.

PINTO, M. S. L.;

OLIVEIRA, R. R.

Análise do momento crítico do setor elétrico brasileiro e suas variações institucionais. In: ENCONTRO ANUAL DA ANPAD, 26., 2002, Salvador. Anais... Salvador: ANPAD, 2002. 1 CD-ROM.

PIRES, J. C. L.

O processo de reformas do setor elétrico brasileiro. Revista do BNDES, v. 6, n. 12, p. 137-168, dez. 1999.
RICHARDSON, R. J.

Pesquisa social: métodos e técnicas. São Paulo: Atlas, 1989.

ROWAN, B.

Organizational structure and the institutional environment: the case of public schools. Administrative Science Quarterly, v. 27, n. 2, p. 259280, 1982.

\section{ROWLEY, T. J.}

Moving beyond dyadic ties: a network theory of stakeholder influences. Academy of Management Review, v. 22, n. 4, p. 887-910, Oct. 1997.

SCOTT, R. W.;

MEYER, J. W.

The organization of societal sectors: propositions and early evidence. In: POWELL, W. E.; DIMAGGIO, P. J. (Eds.). The new institutionalism in organizational analysis. Chicago: The University of Chicago Press, 1991.

STONER, J. A. F.;

FREEMAN, R. E.

Administração. Rio de Janeiro: Prentice-Hall do Brasil, 1989.

VELASCO JR., L.

A economia política das políticas públicas: as privatizações e a reforma do Estado. Rio de Janeiro: BNDES, 1997. Texto para discussão. n. 55.

\section{VINHAES, E.}

A reestruturação da indústria de energia elétrica brasileira: uma avaliação da possibilidade de competição através da teoria de mercados contestáveis. Florianópolis, 1999. Dissertação (Mestrado em Economia Industrial) - Universidade Federal de Santa Catarina. 